\title{
Vehicle State Estimator based regenerative braking implementation on an electric vehicle to improve lateral vehicle stability
}

\author{
Citation for published version (APA): \\ Jansen, S. T. H., van Boekel, J. J. P., lersel, van, S. S., Besselink, I. J. M., \& Nijmeijer, H. (2013). Vehicle State \\ Estimator based regenerative braking implementation on an electric vehicle to improve lateral vehicle stability. In \\ Proceedings of the 27th International Electric Vehicle Symposium \& Exhibition (EVS27), 17-20 November 2013, \\ Barcelona, Spain (pp. 1-12). [6915034] Institute of Electrical and Electronics Engineers. \\ https://doi.org/10.1109/EVS.2013.6915034
}

DOI:

10.1109/EVS.2013.6915034

Document status and date:

Published: 01/01/2013

\section{Document Version:}

Accepted manuscript including changes made at the peer-review stage

\section{Please check the document version of this publication:}

- A submitted manuscript is the version of the article upon submission and before peer-review. There can be important differences between the submitted version and the official published version of record. People interested in the research are advised to contact the author for the final version of the publication, or visit the DOI to the publisher's website.

- The final author version and the galley proof are versions of the publication after peer review.

- The final published version features the final layout of the paper including the volume, issue and page numbers.

Link to publication

\footnotetext{
General rights

- You may freely distribute the URL identifying the publication in the public portal. follow below link for the End User Agreement:

www.tue.nl/taverne

\section{Take down policy}

If you believe that this document breaches copyright please contact us at:

openaccess@tue.nl

providing details and we will investigate your claim.
}

Copyright and moral rights for the publications made accessible in the public portal are retained by the authors and/or other copyright owners and it is a condition of accessing publications that users recognise and abide by the legal requirements associated with these rights.

- Users may download and print one copy of any publication from the public portal for the purpose of private study or research.

- You may not further distribute the material or use it for any profit-making activity or commercial gain

If the publication is distributed under the terms of Article $25 \mathrm{fa}$ of the Dutch Copyright Act, indicated by the "Taverne" license above, please 


\author{
EVS27 \\ Barcelona, Spain, November 17-20, 2013
}

\title{
Vehicle State Estimator based regenerative braking implementation on an electric vehicle to improve lateral vehicle stability.
}

\author{
S.T.H. Jansen ${ }^{1}$, J.J.P. van Boekel $^{2}$, S.S. van Iersel ${ }^{1}$, I.J.M. Besselink ${ }^{2}$, H. Nijmeijer ${ }^{2}$ \\ ${ }^{1}$ TNO Technical Sciences/Automotive, P.O. Box 756, 5700 AT Helmond, The Netherlands, sven.jansen@tno.nl \\ ${ }^{2}$ Eindhoven University of Technology - Department of Mechanical Engineering, The Netherlands
}

\begin{abstract}
The driving range of electric vehicles can be extended using regenerative braking. Regenerative braking uses the electric drive system, and therefore only the driven wheels, for decelerating the vehicle. Braking on one axle affects the stability of the vehicle, especially for road conditions with reduced friction. This paper discusses three control strategies for preventing loss of stability while applying regenerative braking, two of which are using a state estimation algorithm developed by TNO. Experiments have been conducted with a front wheel driven vehicle on a low friction test track. The conclusions concerning the control concepts are however based on simulation results, due to unexpected system behaviour of the test vehicle. The results also indicate that the effectiveness of regenerative braking can be improved in cornering situations by using the vehicle yaw rate as a control signal. Due to hardware limitations, it has not been possible to rank the performance of the individual regenerative braking controllers in practise. It is recommended to further study the control concepts using an improved hardware setup.
\end{abstract}

Keywords: Regenerative braking, Vehicle Dynamics, Simulation, Experiments

\section{Introduction}

The challenge of regenerative braking is to maximize energy recuperation without affecting the vehicle stability adversely [1]. Since 2011, the Eindhoven University of Technology is using an in-house developed battery electric VW Lupo EL [2] for educational and research purposes. The relatively high motor power of $50 \mathrm{~kW}$ and available motor torque makes this vehicle well suited to investigate drive train control concepts and it is equipped with a regenerative braking system [3]. The regenerative braking system is able to achieve a high amount of front-wheel deceleration, causing high amounts of wheel slip that may result in loss of directional stability, as shown in in Figure 1.

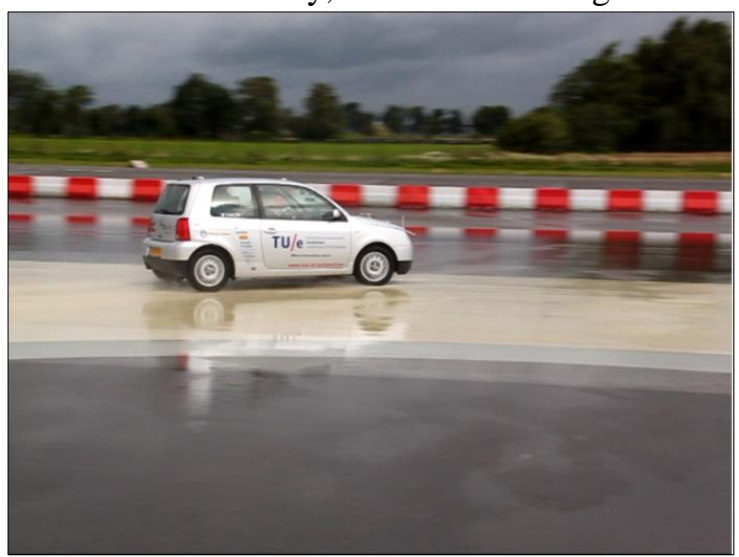

Figure 1: Understeering due to regenerative braking. 


\subsection{Vehicle configuration}

The test vehicle is front wheel driven, where the conventional drive train is replaced by batteries, a single gear transmission, an electric motor and some electric components to control the drive system and charge the batteries. The basic vehicle drive train layout is shown in Figure 2.

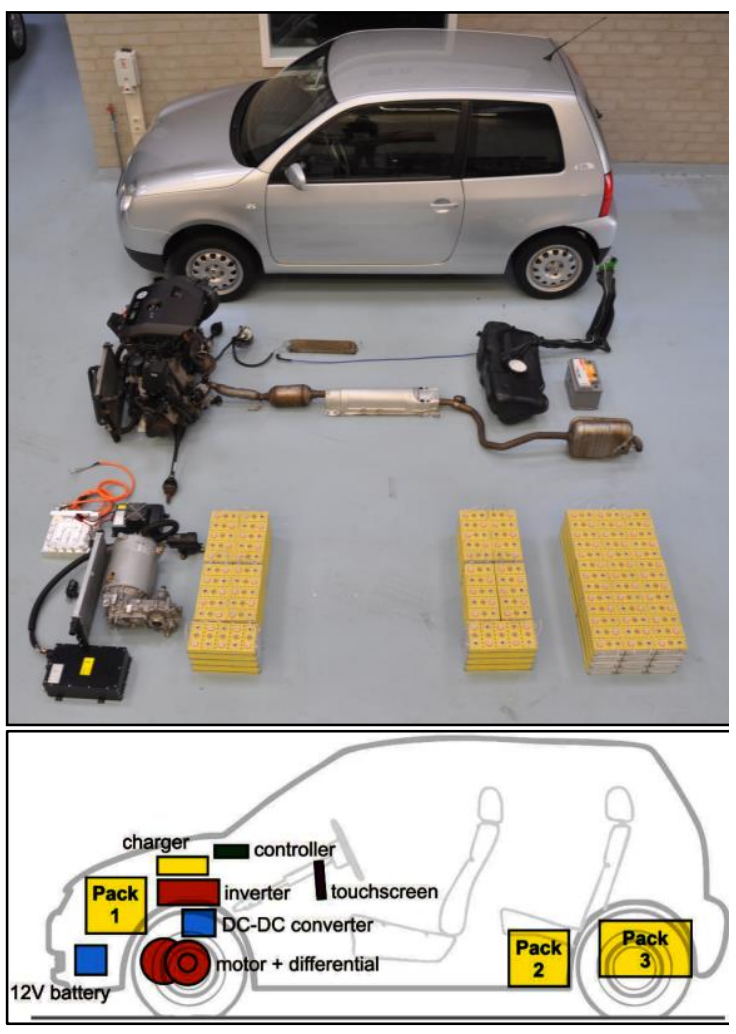

Figure 2: Vehicle drive train layout [2].

\subsection{Drive torque control}

A schematic overview of the electric drive system is shown in Figure 3. The drive torque command is controlled by a Programmable Logic Controller (PLC), which communicates a torque request to the inverter via $\mathrm{CAN}$ messages. The inverter controls the motor current, resulting in a torque that is transmitted to the wheels via an open differential.

The PLC defines the drive and brake torque in relation to positions of brake and throttle pedal, and includes traction control by scaling the requested output torque based on detected wheel slip. This control system operates also for regenerative braking, and is one of the control concepts considered in this paper. This and other regenerative braking control concepts operate by changing the scaling method of the output torque.

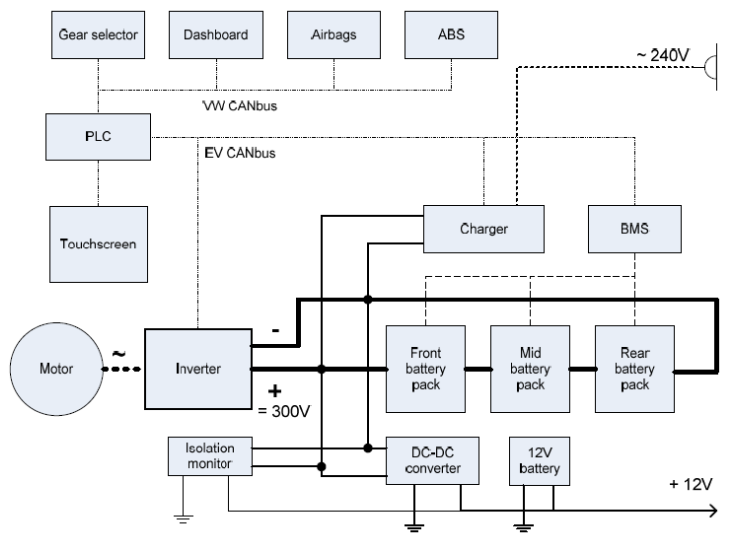

Figure 3: Electric drive system [2].

The control concepts are explained in section 2 . Two of the methods are using signals generated by Vehicle State Estimation (VSE) which is explained in section 3. The controller development and evaluation is done using a simulation model which is described in section 4. Experiments are discussed in section 5, and the control evaluation is described in section 6. Finally conclusions \& recommendations are given in section 7 .

\section{Control concepts}

Regenerative braking is applied in electric vehicles to recuperate kinetic energy for extending the driving range of the vehicle. The amount of regenerative braking torque has to be controlled to prevent an excess of tyre slip resulting in loss of lateral vehicle stability (especially during cornering). A wheel slip based control concept is described in Section 2.1. The two VSE based control strategies are discussed in Section 2.2.

A schematic drawing of the applied control concepts is shown in Figure 4. As can be seen in the figure, the requested motor torque $T_{m}$ is determined based on, among others, the output value of the regenerative braking controllers. The symbol $\tau$ represents a torque scaling value between 0 and 1 and is used to limit the requested motor torque.

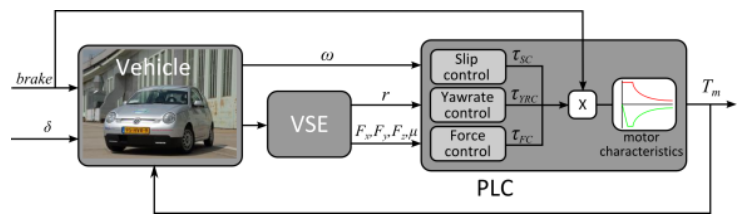

Figure 4: Overview of control concepts. 
The control concepts are created using the following vehicle based signals:

- Wheel angular velocities $(\omega)$

- Steer angle $(\delta)$

- Yaw rate $(r)$

Additionally the Vehicle State Estimator uses the vehicle lateral and longitudinal acceleration.

\subsection{Slip control}

The slip control concept adjusts the amount of regenerative braking based on the difference in speed between the driven front wheels and nondriven rear wheels. The difference in angular velocity indicates the slip of the front wheels, using equation (1).

$s_{S C}=\frac{\left|\omega_{f}-\omega_{r}\right|}{\max \left(w_{\text {free }},\left|\omega_{r}\right|\right)} \times 100 \%$

In this equation, $\omega_{f}$ and $\omega_{r}$ represent the average of front wheel angular velocity and average of rear wheel angular velocity respectively. The parameter $\omega_{\text {free }}$ specifies the threshold angular velocity preventing division by zero and allowing more slip at low speeds.

The aim of the controller is to keep the longitudinal slip $s_{S C}$ restricted to a defined slip range from $s_{S C, \min }$ to $s_{S C, \max }$ where the lateral tyre force is not (much) affected. This is done by linearly reducing the motor torque scaling value $\tau_{S C}$ as shown in Figure 5. For the conditions discussed in this paper, the lower slip limit is set to $2 \%$ whereas the upper slip limit is set to $5 \%$.

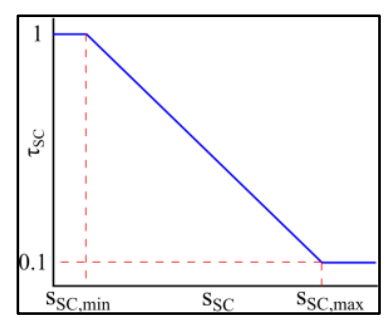

Figure 5: Slip based scaling values.

\subsection{VSE based strategies}

Two control concepts use signals generated by a Vehicle State Estimator. The first VSE-based strategy uses estimations for the road friction coefficient $\mu$ and applied tyre forces to the vehicle. The second strategy considers the vehicle yaw rate and a reference yaw rate $r$ is calculated using estimated model parameters from the VSE. Both strategies are described below in more detail.

\subsubsection{Force control}

The force control concept limits the amount of regenerative braking torque by considering the tyre force potential of the front wheels, and determines the remaining capacity for braking (i.e. force margin) based on the currently applied forces.

The tyre force potential is calculated for each driven wheel using the estimated road friction $\mu$ and the vertical tyre force $F_{z}$ including effects of load transfer due to vehicle accelerations. The estimated tyre slip forces in longitudinal and lateral direction $\left(F_{x}, F_{y}\right)$ are used to assess the magnitude of total slip force, which is subtracted from the tyre force potential to obtain the force margin in accordance with equation (2).

$F_{\text {margin }}=\frac{\mu \mathrm{F}_{z}-\sqrt{F_{x}{ }^{2}+F_{y}^{2}}}{\mu \mathrm{F}_{z}}$

The front wheel with the smallest force margin defines the regenerative torque scaling value $\tau_{F C}$ using a function that is displayed in Figure 6. A sensitivity factor $k$ is used to adjust the reduction of the regenerative braking torque.

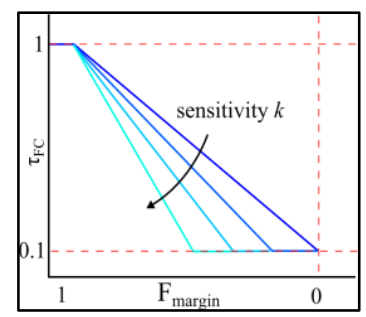

Figure 6: Scaling values in relation to force margin with different sensitivity values.

\subsubsection{Yaw rate control}

The yaw rate control concept reduces regenerative braking when potential instabilities are assessed from the yaw rate signal. To account for straight line braking situations it is combined with the slip control concept as described in Section 2.1 but with adjusted settings for cornering conditions.

The measured yaw rate $r_{e s t}$ is compared to a reference yaw rate $r_{\text {ref }}$. The reference yaw rate is obtained from a vehicle model that uses parameters obtained from the VSE, considering the estimated road friction conditions and non-linear tyre characteristics, see Figure 8 . The reference yaw rate considers the vehicle response without any effect of regenerative braking. 
The deviation of the estimate yaw rate from the reference yaw rate is used during the regeneration phase. The deviation yaw rate $r_{\text {diff }}$ is simply calculated using equation (4).

$r_{\text {diff }}=\left|r_{\text {est }}-r_{\text {ref }}\right|$

A look-up table is used to define the torque scaling $\tau_{Y R C}$ in relation to the yaw rate deviation $r_{\text {diff }}$ as displayed in Figure 7.

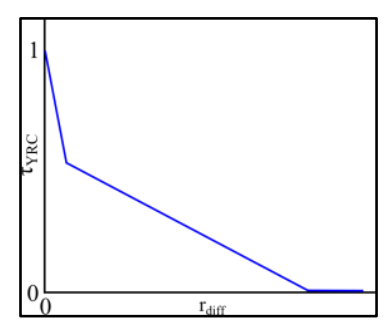

Figure 7: Yaw rate controller scaling values.

\section{Vehicle State Estimation}

Vehicle State Estimation (VSE) is a method of sensor fusion that can be used for signal enhancement (quality, reliability, etc.) or for generating signals that cannot be obtained by sensors available on the vehicle. TNO has developed a concept in the Vehicle Dynamics domain, which uses signals available from Electronic Stability Control systems using an Extended Kalman Filter Approach [4]. An output of this concept is vehicle body slip angle, and it is used on production vehicles as well as for integrated vehicle dynamics control applications including active suspension developed by TNO [5].

The setup of the VSE as used in this study is depicted in Figure 8. The core of the VSE is a model representation of the vehicle, which together with the sensor setup, is dedicated for the application. Recently the concept has been extended for electric vehicles to support brake blending and vehicle stability functions by control of the electric motor torque [6].

The extension for electric vehicles is done by inclusion of the first order driveline dynamics. Specifically under regenerative braking an enhanced assessment of the tyre friction potential is realized.

The regenerative control concepts discussed in this paper use the estimated tyre forces and tyre friction potential, as well as the estimated vehicle yaw rate which is enhanced compared to the yaw rate sensor signal.

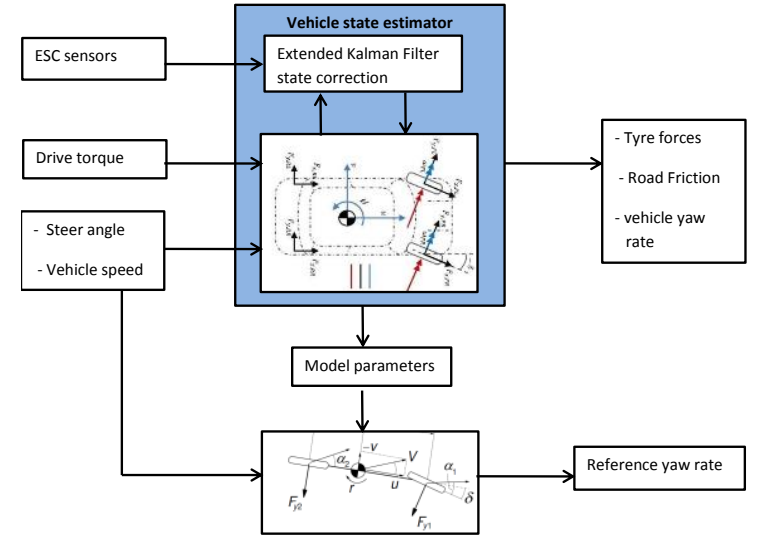

Figure 8: Setup of Vehicle State Estimator.

\section{Simulation setup}

For the development of the regenerative braking concepts a multibody simulation model of the vehicle is used. The multibody model is defined in MATLAB/SimMechanics and has been developed during various student projects at the Eindhoven University of Technology [3], [7].

The simulation model is depicted schematically in Figure 9 and contains a detailed representation of the mechanical properties that are related to vehicle dynamics (i.e. tyres, suspension, main body and drive train). The drive control and sensors are modelled in addition to these components.

To investigate the controllers proposed in this paper, the model is extended with signals from TNO's VSE algorithm, and the three control concepts for regenerative braking have been implemented using Simulink functions.

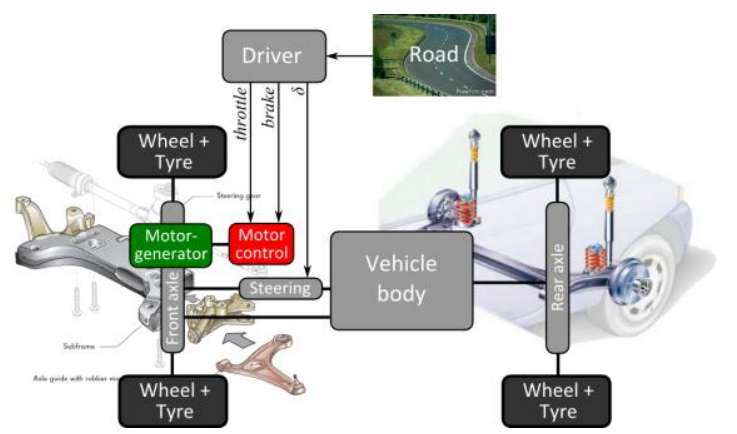

Figure 9: Schematic representation of SimMechanics model.

Based on experimental results the model has been validated for steering response and braking response. This is described in the next sections. 


\subsection{Steering response validation}

The steering response is validated using the TNO Tyre Estimator [8] with optimisation of Magic Formula tyre model parameters in the SimMechanics model. The vehicle model is simulated with the recorded steering angle, throttle signal and brake signal acquired from manoeuvres carried out with the actual vehicle on the test track. Using this input data comparison of measurement data and simulation data can be made. The TNO Tyre Estimator is used to derive the values of effective cornering stiffness from the measurement data and simulation data respectively.

The cornering stiffness from simulation $\left(C_{F \alpha, \text { model }}\right)$ is compared to the cornering stiffness of the measurement $\left(C_{F \alpha \text {,meas }}\right)$ and the ratio of the two values is used to adjust the cornering stiffness of the tyres in the simulation model. The procedure is depicted in Figure 10.

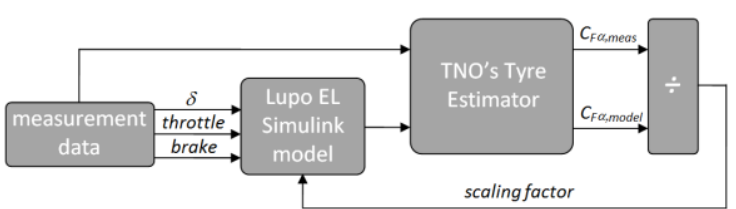

Figure 10: Optimisation scheme for vehicle steering response.

Figure 11 shows the comparison of the initial model and optimized model with measurement for yaw rate response and lateral acceleration response respectively. In the figures the dashed lines indicate the measured signals where the steering angle and velocity are used as inputs to the Simulink model. The red solid lines show the initial model response whereas the blue solid lines represent the optimized model response. As can be seen a good match with measurements can be obtained by adjusting only tyre cornering stiffness parameters.

\subsection{Electric drive train model}

A conceptual regenerative braking model has been developed following the strategy described in [3]. Based on the brake pedal position and the controller scaling value, a requested torque value between zero and one is determined. Using the torque characteristics of the electric motor, the motor torque $T_{m}$ is calculated as a function of the motor's angular velocity $\omega_{m}$ (see Figure 12).

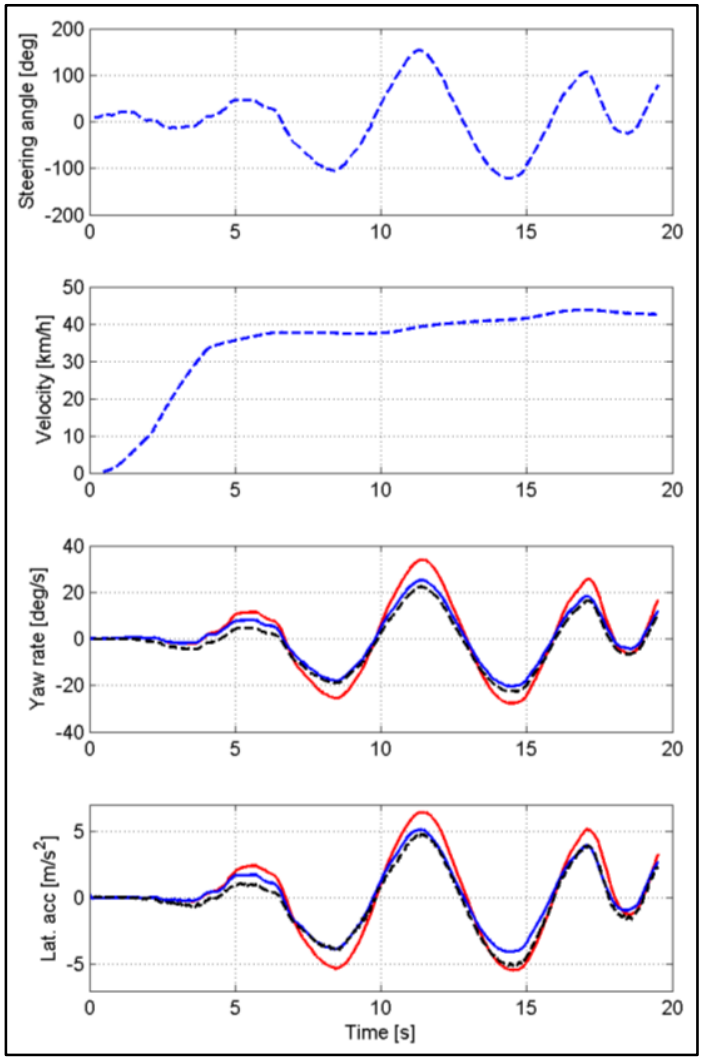

Figure 11: Initial (red line) and optimized (blue line) model results for a steering manoeuvre. The dashed lines represent the measurements.

In reality the energy recuperation characteristics are dependent on other factors (battery, inverter, etc.), but for this study these components are not considered.

The drive train model has been validated using a pedal operated regenerative straight line braking manoeuvre without any feedback controller being active. The measured vehicle response is shown in Figure 13.

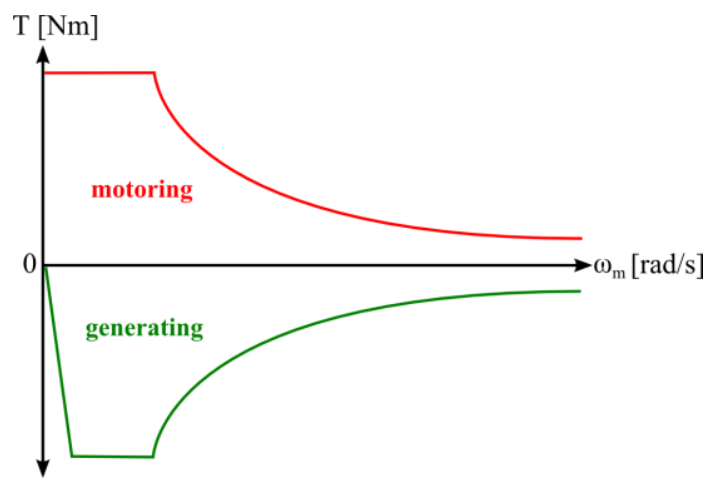

Figure 12: Electric motor characteristics. 


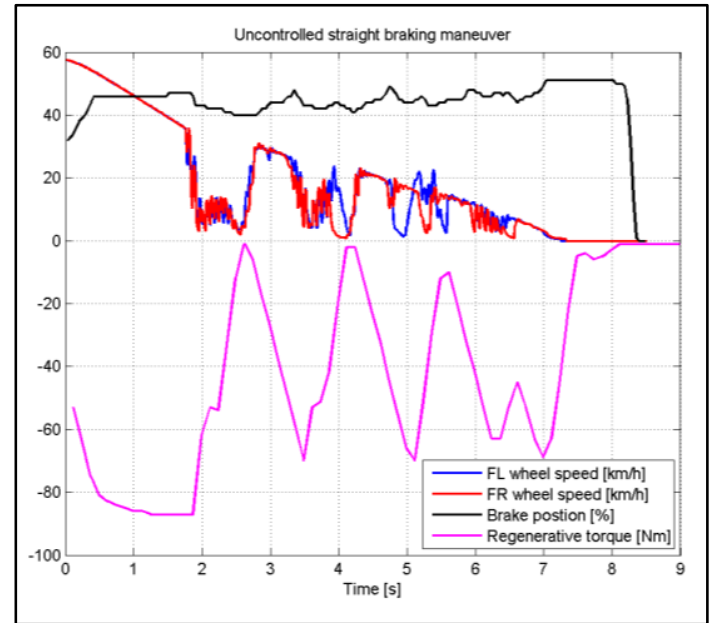

Figure 13: Experimental results from a pedal operated regenerative straight line braking manoeuvre.

As can be seen in Figure 13, after the braking pedal is actuated, the regenerative torque (reconstructed from the motor current) increases to a magnitude of about $87 \mathrm{Nm}$ which causes the front wheels to slip and loose traction at $\mathrm{t}=1.8$ seconds. Due to the fact that no current can be generated by the motor at zero motor speed, the regenerative torque decreases to zero at $\mathrm{t}=2.6$ seconds. Since the vehicle has not yet reached standstill the driver lifted the brake pedal somewhat to allow the front wheels to speed up again and the amount of regenerative torque increases again. From the motor torque signal it can be seen that the rate of change is limited to approximately $80 \mathrm{Nm} / \mathrm{s}$.

This rate of change limitation in motor torque is implemented in the simulation model and the results for a similar manoeuvre are shown in Figure 14.



Figure 14: Simulated regenerative straight line braking manoeuvre on a road with reduced friction.
It is noticeable in the simulation results that the front left and right wheel angular velocities are different from each other during certain time intervals, which is due to some asymmetry in the simulation model (e.g. tyre characteristics). Furthermore, during braking negative angular velocities are observed at some stages. This behaviour can occur because the brake torque is applied on the input shaft of the open differential gear, and no further braking is applied on the individual wheels (connected to both output shafts).

\section{Experiments}

Experiments have been conducted on a proving ground in the vicinity of Eindhoven where low friction road surfaces are available. The test vehicle was equipped with additional sensors to obtain a full set of vehicle dynamics motion signals, i.e. high precision yaw rate, lateral and longitudinal acceleration and vehicle slip angle. A dSPACE system has been installed for data recording and for running the Vehicle State Estimator and VSE based regeneration strategies.

Communication with the vehicle drive control systems has been achieved via the CAN bus and a customer grade ESC sensor provides the vehicle motion signals required by the VSE.

\subsection{Control application}

The experiments to evaluate the control concepts have been executed on a low friction road surface only.

As was made clear in Chapter 2, all three regenerative braking controllers output a scaling value between 0 and 1 . This value is used to scale the regenerative braking request to the inverter in order to limit the amount of regenerative torque.

When testing, it appeared that the delay of the inverter may vary between 0.2 and 0.6 seconds during consecutive test drives. This made controller tuning a difficult task, and also the comparison of the performance of different regeneration strategies will be challenging. Some test results are discussed nonetheless to give an impression of real-life results.

The main response signals of the slip based controller are shown in Figure 15. Regenerative braking is initiated by operating the brake pedal. An increase of the pedal displacement is applied to provoke wheel slip. The scaling value is displayed as a percentage and is in this case dependent on the 
slip (see Eqn.1). As soon as regenerative braking leads to excessive wheel slip the scaling value is reduced to $10 \%$. Then, a sequence of small increase and decrease of the scaling value is observed until the vehicle comes to a halt. The regenerative torque varies between 15 and $30 \mathrm{Nm}$.

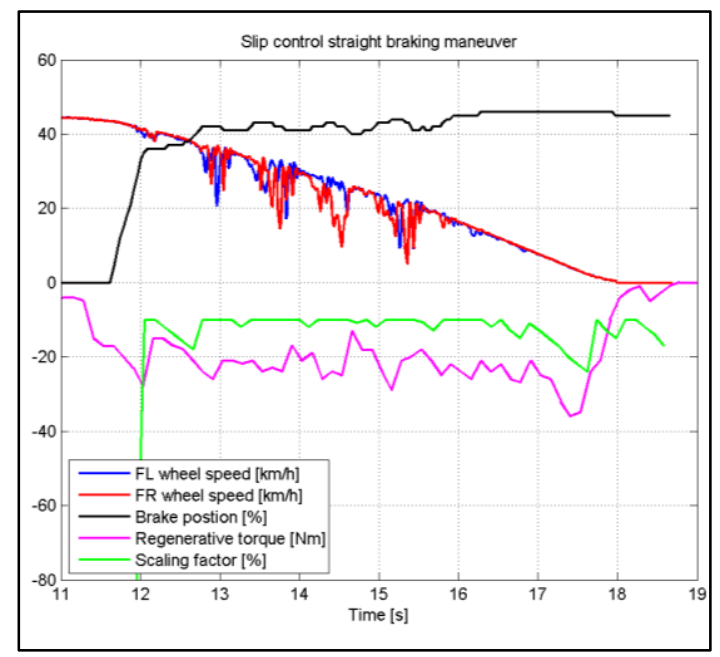

Figure 15: Experimental results of slip controller for a straight line braking manoeuvre.

A regenerative braking sequence with the force controller is displayed in Figure 16 for a corner braking manoeuvre.

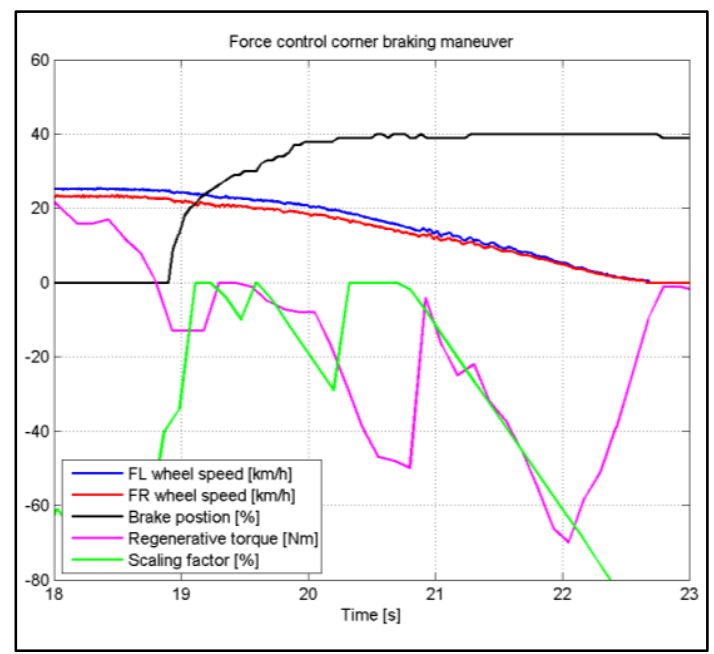

Figure 16: Experimental results of force controller for a corner braking manouvre.

As can be seen in Figure 16 the vehicle speed is reduced without any indication of wheel slip in the wheel angular velocity signals. The difference between left and right angular velocity is caused by the increased tyre deflection of the outer wheel due to the cornering load transfer.
Furthermore Figure 16 shows that the magnitude of regenerative torque brake force can be increased when vehicle speed and lateral force due to cornering reduces. When approaching standstill speed the regenerative capacity decreases as also shown in the motor characteristic, see Figure 12. Even though the inverter delay was not consistent the VSE-based force controller performed adequately.

\section{Simulation based evaluation of control concepts}

As mentioned in the previous section, the inverter of the experimental vehicle shows unexpected nonconstant delays. A simulation study is therefore performed to be able to evaluate the performance of the different controllers in a more consistent environment. Most simulations are executed using a fixed 0.2 second delay in inverter response as well as the torque rate restrictions that are discussed in Section 4.2. The control performance is evaluated for a straight line braking manoeuvre and a corner braking manouvre, as further discussed in the next sections. A few simulations are executed with zero inverter delay to assess the impact of the delay on the control performance

\subsection{Straight line braking}

Straight line braking is simulated on a road with initially a high friction and a reduction of friction is initiated at a simulation time of 6 seconds, as depicted in Figure 17.

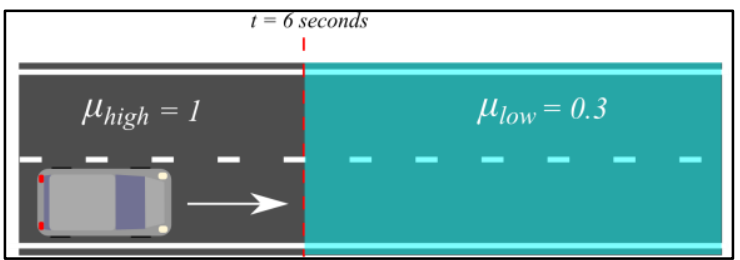

Figure 17: Road friction for straight line braking.

For this straight line braking manoeuvre the yaw rate controller is not discussed as it functions similar to the slip controller in this scenario.

\subsubsection{Slip control}

Figure 18 shows the results for the slip controller. As can be seen the regenerative torque is decreased shortly after the transition to low friction. The limited rate of change in torque clearly appears in the results. 


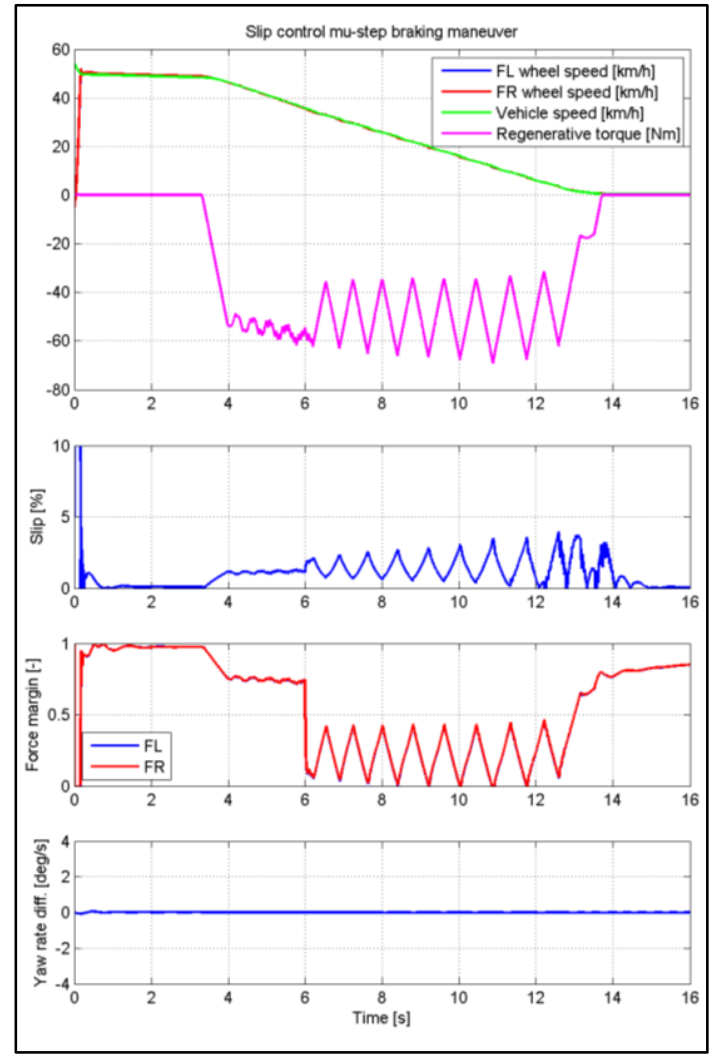

Figure 18: Simulation result of slip controller for a straight line braking manoeuvre.

When the transition to the low friction surface is encountered, the slip increases and the regenerative torque is reduced, and generally the amount of slip remains small. After this disturbance the controller shows cyclic behaviour, while generating a torque which on average is lower than the regenerative torque on high friction. It can be seen that the force margin initially is quite large and is reduced to smaller values as soon a regenerative braking is applied. The yaw rate deviation is virtually zero, as can be expected in a straight line scenario.

\subsubsection{Force control}

The results for the force controller are shown in Figure 19. It can be seen that the regenerative torque has increased to a higher level on the high friction road than the slip controller, however still a considerable force margin remains. At this stage the regenerative torque is limited by the motor capacity. When the road friction is reduced, the regenerative torque reduces over a large range than the slip controller, taking more time due to the rate limitation.
As a result a larger amount of slip is observed during the transition, initially settling at similar values as shown for the slip control, and finally grows when the vehicle approaches standstill.

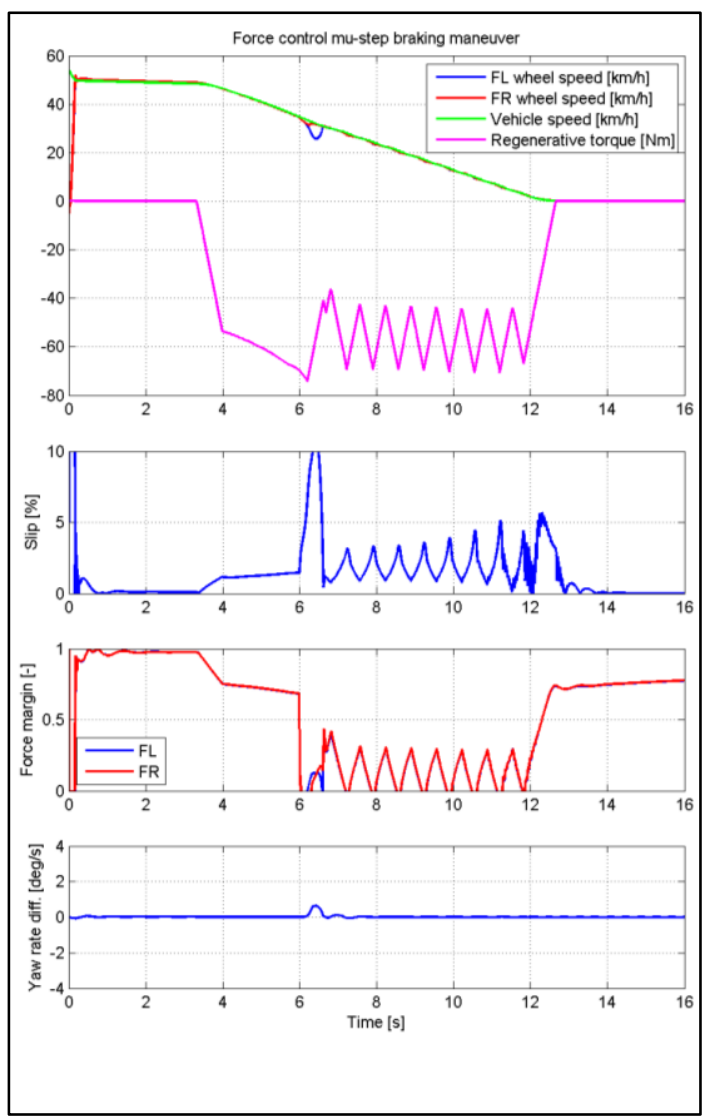

Figure 19: Simulation result of force controller for a straight line braking manoeuvre.

A comparison of both regenerative braking control concepts is shown in Figure 20 for time to standstill and longitudinal acceleration respectively, and it can be seen the force controller results in the shortest time to standstill, shorter than the uncontrolled vehicle. The slip controller actually increases the braking distance.

The fluctuations in vehicle acceleration are similar for both controllers (slightly smaller for the force controller), and are directly related to the cyclic behaviour observed in the regenerative torque.

\subsection{Braking during cornering}

A braking manoeuvre is carried out in during cornering on a low friction road surface at an initial speed of about $50 \mathrm{~km} / \mathrm{h}$ and a steering angle such that vehicle is close to the cornering limit. The regenerative braking is evaluated in this cornering situation for all three controllers. 


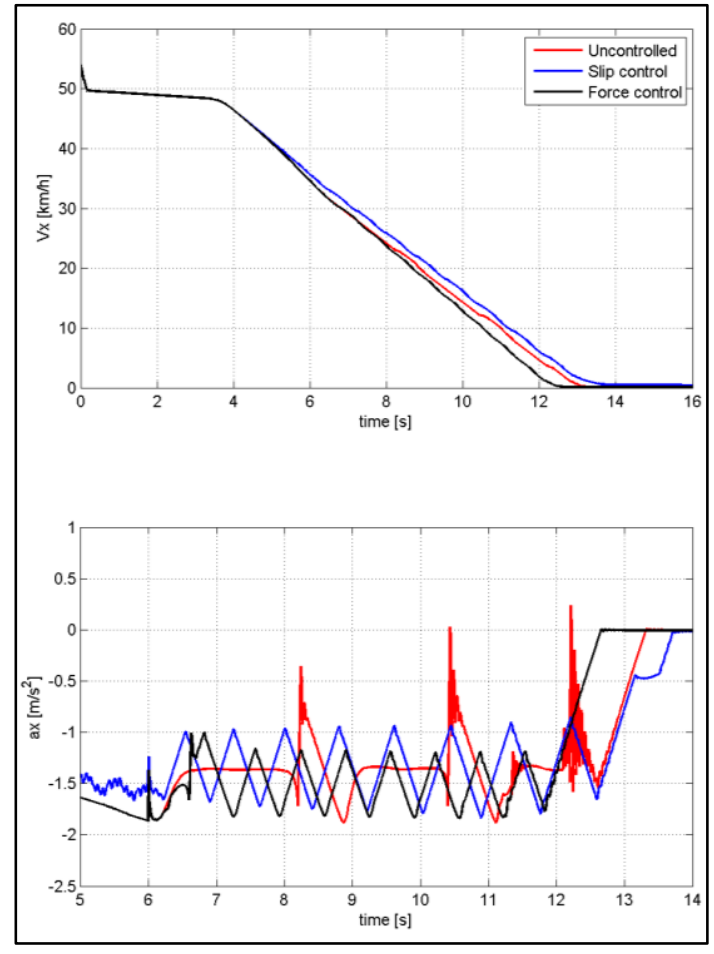

Figure 20: Comparison of speed profile from slip controller and force controller for a straight line braking manouvre.

First the results of a simulation without control are discussed using signals displayed in Figure 21. The initial vehicle speed is set to $50 \mathrm{~km} / \mathrm{h}$ when steering is applied. When lateral acceleration and yaw rate reach their steady state values, regenerative braking is activated on the front wheels.

The longitudinal slip at the front wheels increases quickly due to the low friction, resulting in a diminishing lateral force that can be transferred at the front wheels. As a result the yaw rate decreases to zero, which means a large deviation to the reference yaw rate. Effectively the vehicle is understeering heavily and roughly continues in a straight path, away from the circular track (see also the picture in Figure 1).

When the motor speed is very low, the regenerative braking capacity approaches zero and the wheels speed up again. This sequence is repeated until finally the vehicle comes to a halt.

During this manoeuvre it can be seen that the force margin reduces to zero several times, indicating that the front wheels tyres fully exploit the friction potential.

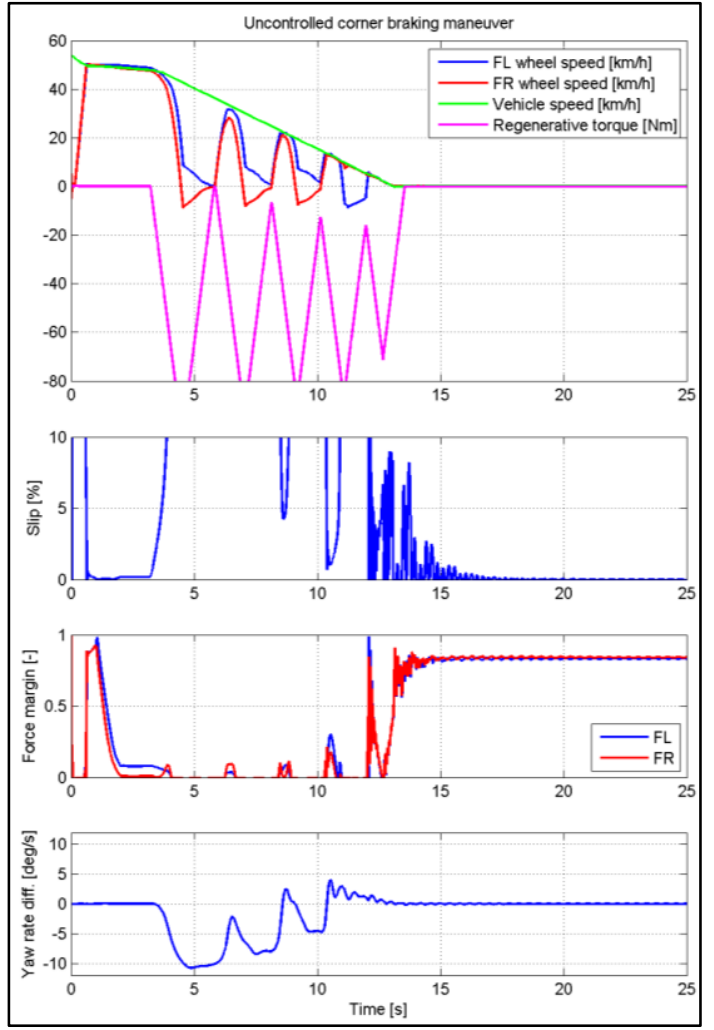

Figure 21: Results of corner braking manouvre without control.

\subsubsection{Slip control and force control}

The results of the slip controller for the corner braking manoeuvre are depicted in Figure 22.

The result is a different amount of speed variation of the front wheels. The test vehicle is equipped with a central motor and an open differential, resulting in an equal torque distribution between both wheels. The inner wheel is unloaded due to the lateral acceleration, and can transfer less longitudinal force to the road, resulting in a larger speed reduction, and also smaller force margin. The regenerative torque shows the same cyclic behaviour as in the straight line braking manoeuvre.

The results for the force controller are depicted in Figure 23. As can be seen, the initial control of regenerative brake torque is smooth, suggesting a better robustness than the slip controller. When the regenerative braking torque is increased above a certain threshold the cyclic behaviour is triggered as observed in the straight line braking manoeuvre. 

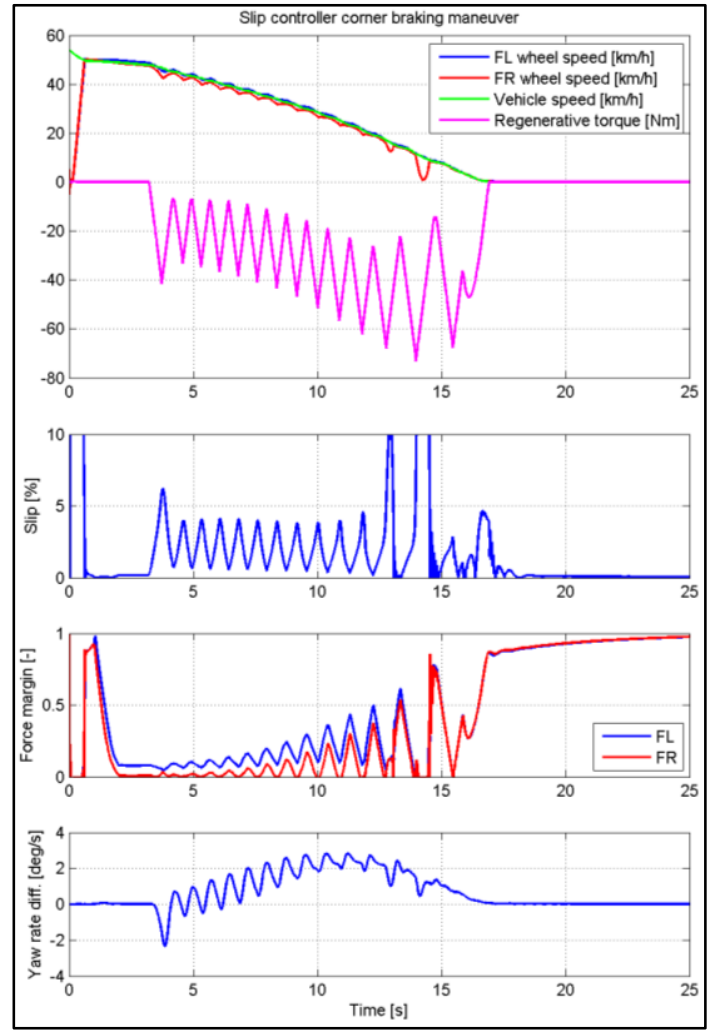

Figure 22: Results of slip controller for corner braking manouvre.

\subsubsection{Yaw rate control}

The results of the yaw rate control concept are depicted in Figure 24. This controller does not show any cyclic behaviour in the regenerative torque. Apparently the front right wheel is kept close to the friction limit without excessive slip, and without significant deviation from the reference yaw rate. At very low speed the yaw rate becomes small and the full regenerative torque is applied resulting in a short period of slipping of the front-left wheel. Probably due to the less fast varying nature of the vehicle yaw rate, no cyclic behaviour is experienced.

A comparison of the different control concepts with respect to the path tracking and yaw rate is made in Figure 25. The reference path corresponds to the reference yaw rate.

Clearly it can be seen that without control the vehicle deviates immediately from the reference path. Furthermore, the yaw rate controller demonstrates the shortest braking distance. The slip controller and force controller show similar paths, with a longer braking distance for the force control.

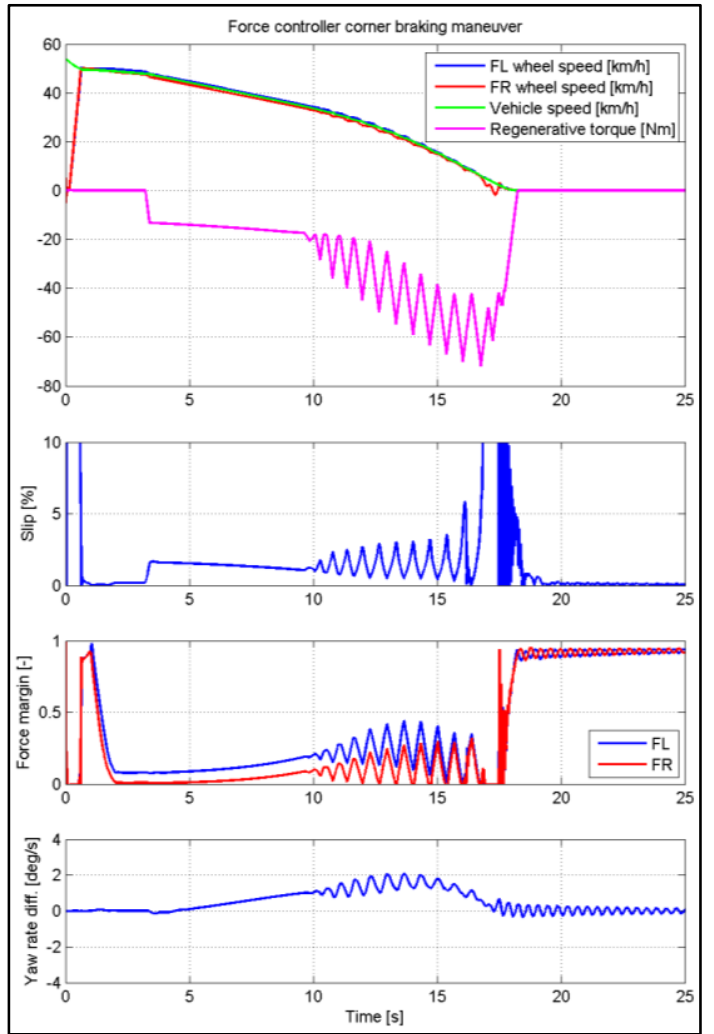

Figure 23: Results of force controller for corner braking manoeuvre.

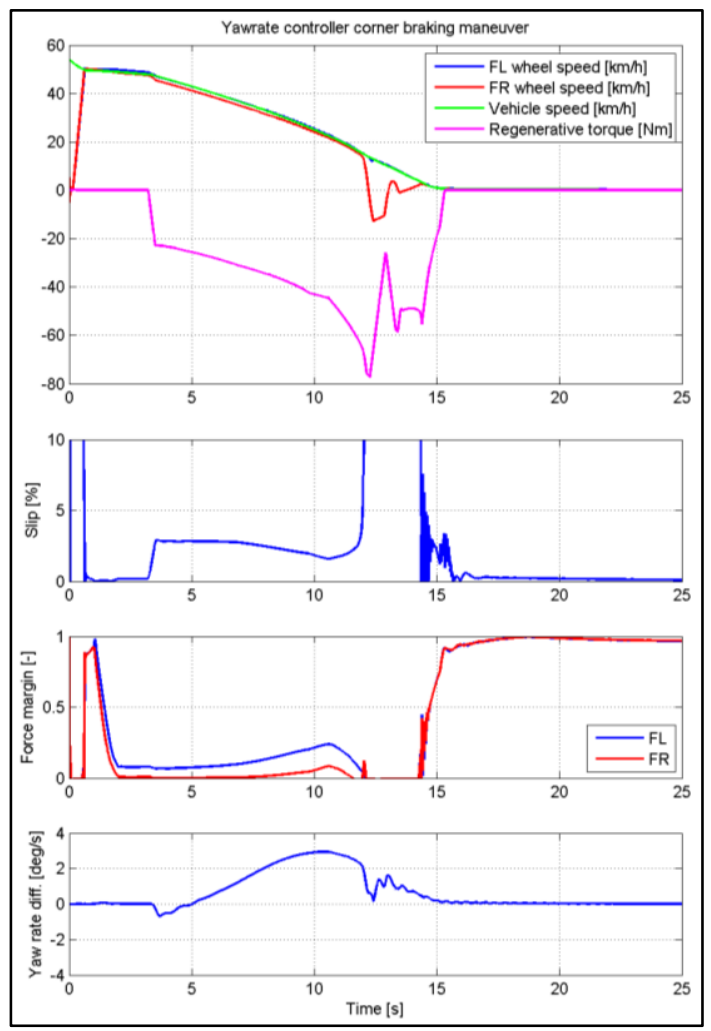

Figure 24: Results of yaw rate controller for corner braking manoeuvre. 


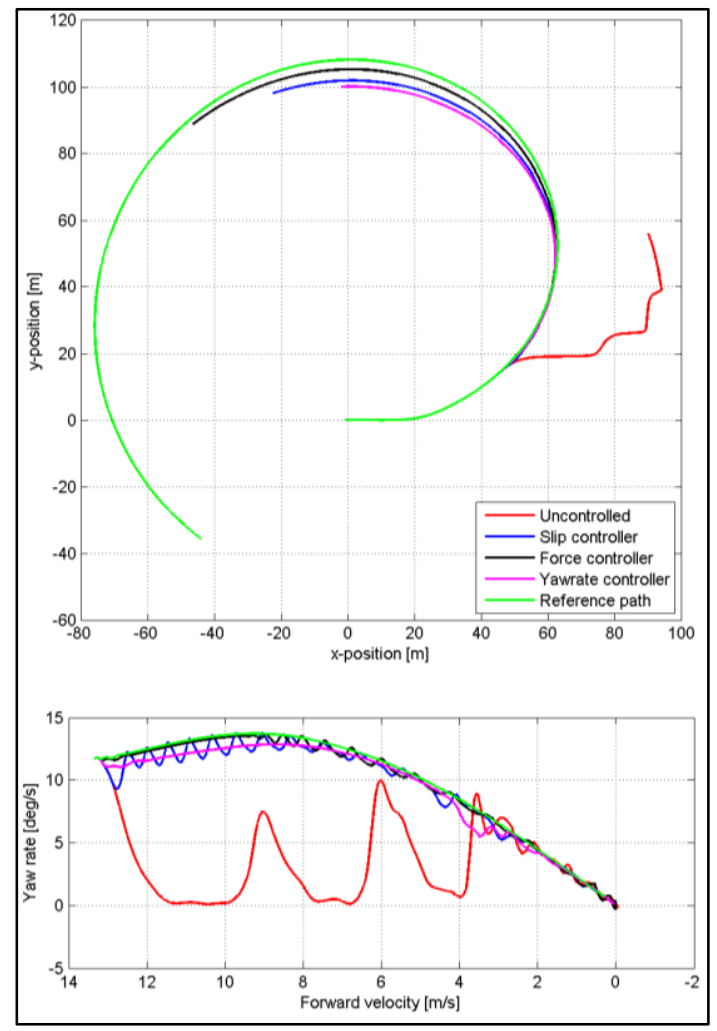

Figure 25: Position trace and yaw rate of the vehicle using different controllers for corner braking manoeuvre.

When comparing the yaw rate versus speed of the controllers in the bottom graph of Figure 25, it can be seen that the yaw rate in case of force control remains closest to the reference signal, and the variations are smaller than when using slip control. The regenerative braking using yaw rate control shows a deviation which is directly related to the tuning of the yaw rate controller. Generally it can be concluded that the optimal regenerative braking concept will be a compromise between yaw rate deviations and stopping distance.

\subsection{Inverter delay}

Finally some simulations have been conducted using zero inverter delay and a comparison is made to assess the impact of inverter delay on the regenerative braking performance. The results are shown for a straight line braking manoeuvre in Figure 26, and as can be seen the cyclic behaviour no longer occurs with zero inverter delay. The overall control performance is improved for zero delay, even without any adaptation of the control settings.

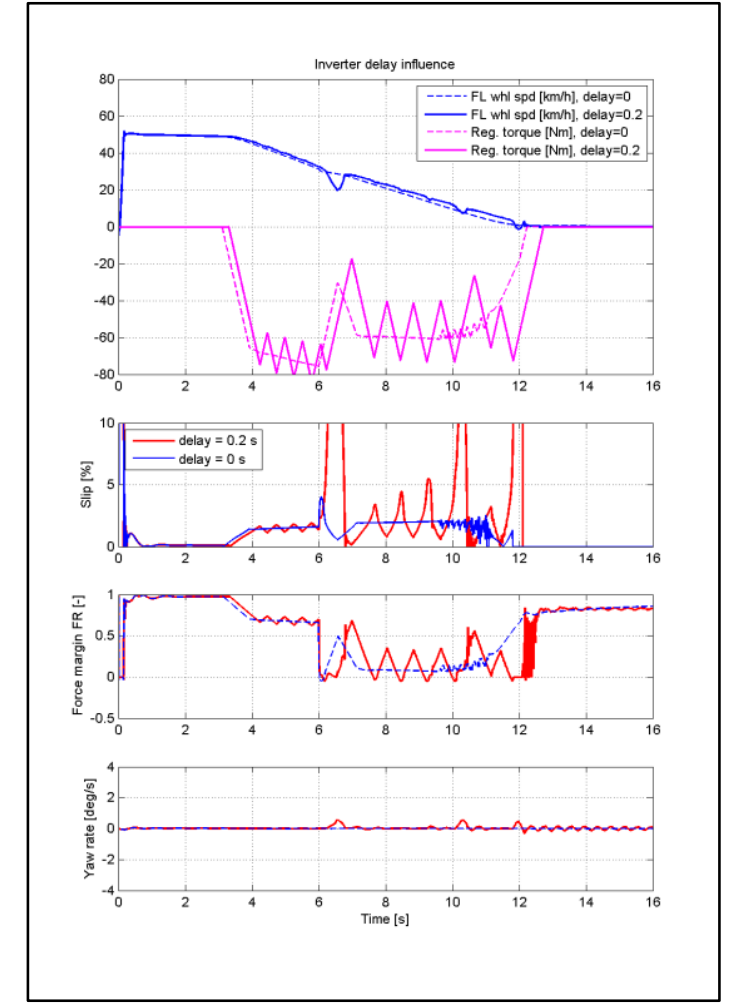

Figure 26: Comparison of results with different inverter delay for a straight line braking manoeuvre.

For the corner braking manoeuvre it appears that with zero inverter delay all regenerative braking control concepts show a very similar path and yaw rate as shown in Figure 25. Some adaptation in the settings the yaw rate control concept was however required.

When comparing the stopping distance for this manoeuvre a significant improvement is observed for both the slip control and force control concepts. The results are summarized in Table 1, and as can be seen the difference in the stopping distance between control concepts is largely eliminated with zero inverter delay.

Table 1: Stopping distance for corner braking manouvre with different inverter delay.

\begin{tabular}{|l|l|l|}
\hline & Delay 0.2 sec. & Delay 0 sec. \\
\hline Slip control & $144 \mathrm{~m}$ & $134 \mathrm{~m}$ \\
\hline Force control & $163 \mathrm{~m}$ & $135 \mathrm{~m}$ \\
\hline Yaw rate control & $133 \mathrm{~m}$ & $136 \mathrm{~m}$ \\
\hline
\end{tabular}

Based on these results it is clear that inverter delay has a dominant impact on the control performance and that further analysis is required to assess the full potential of the different control concepts for small inverter delay values. Additionally, for small inverter delay the rate limitation of torque change seems less relevant for the control performance. 


\section{Conclusions \& recommendations}

The conclusions concerning the control concepts for regenerative braking are mainly based on simulation results due to the unexpected system behaviour of the test vehicle.

For straight line braking a controller using tyre slip constructed based on wheel angular velocity sensors is compared to a controller using tyre force obtained from Vehicle State Estimation. The performance of both controllers is dominated by delay effects of the inverter. Results from a cornering scenario, and a comparison with performance for zero inverter delay shows that a yaw rate based control concept is less affected by inverter delay. The difference in performance of the control concepts reduces very much when zero inverter delay is applied. The results nonetheless suggest that regenerative braking can be optimized for cornering scenarios when considering the vehicle yaw rate in the control setup.

To come to a conclusion of the true potential of the control concepts it is recommended to further study all control concepts using a hardware setup with a faster and more consistent torque command response and also include a wider variety of manoeuvres.

\section{Acknowledgments}

The authors would like to thank Paul van Oorschot for realising the control implementation on the VW Lupo EL and Robby Janssen for his contribution in vehicle testing.

\section{References}

[1] M. Kamachi, H. Miyamoto, H. Yoshida, Development of Electric Vehicle for Onroad Test, 9th International Symposium on Advanced Vehicle Control, Kobe, Japan, October 2008

[2] I.J.M. Besselink, P. van Oorschot, E. Meinders, and H. Nijmeijer, Design of an efficient, low weight battery electric vehicle based on a VW Lupo 31, EVS-25 Shenzhen, China, November 2010

[3] K. Broeksteeg, Parallel regenerative braking control for the TU/e Lupo EL, D\&C report 2012.066, Eindhoven University of Technology, November 2011.
[4] J. Zuurbier, N.J. Schouten, R. Leenen. Central State Estimator for Vehicle Control Systems. Proceedings, JSAE (paper number 20075048), May 2007

[5] M. Alirezaei, A. Teerhuis, R. Wouters, Integrated Vehicle Dynamics Control using Brake-byWire and Active Suspension, $22^{\text {nd }}$ Aachener Kolloquium, Aachen, Germany, October 2013

[6] Intelligent Dynamics for Electric Vehicles, http://www.id4ev.eu/

[7] A.D. George, SimMechanics Simulation Model of the VW Lupo 3L, user manual, D\&C 2012.030, Eindhoven University of Technology, July 2012.

[8] S. Jansen, Validation of Tyre Force Estimator, Vehicle Dynamics Expo Stuttgart 2008 www.vehicledynamics-expo.com/08vdx_conf

\section{Authors}

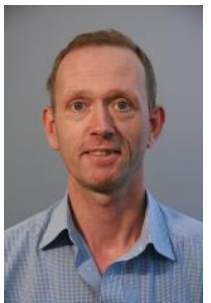

Sven Jansen obtained his MSc degree in 1990 at the Delft University of Technology on the topic of dynamic tyre modelling under supervision of $\mathrm{dr}$. Hans Pacejka. Since then he is employed at TNO and he developed various vehicle control applications using simulations and experiments, and most recently he is coordinating research projects related to vehicle state estimation.

Joost van Boekel is currently graduating under supervision of dr. Igo

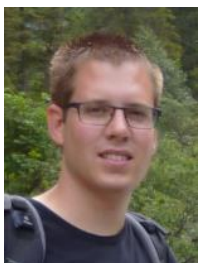
Besselink at the Eindhoven University of Technology on various topics regarding regenerative braking of the in-house developed electric VW Lupo EL. His main interests are in the field of vehicle dynamics and electric vehicles innovations in general. 